\title{
Los sesgos de género en el sistema financiero y tributario español: Propuestas de solución ${ }^{(*)}$
}

\section{Gender biases in the Spanish financial and tax system. Proposals of solution}

\author{
Julia María Díaz Calvarro(*) \\ España - Universidad de Extremadura
}

\begin{abstract}
Resumen: El sistema financiero español presenta, tanto en su estructura presupuestaria e impositiva, como en las medidas calificadas de "acción positiva", sesgos de género que perpetúan el papel de la mujer en el ámbito de los cuidados, suponiéndole costes de oportunidad en el desarrollo de su esfera profesional y personal. El análisis de alguno de los ejemplos más paradigmáticos y la propuesta de diversas soluciones desde la economía feminista y la fiscalidad de género son el objeto de este trabajo.
\end{abstract}

Palabras claves: Sistema Financiero - Presupuestos - Tributos - Género - Sesgos de Género.

\begin{abstract}
The Spanish financial system, both in its budgetary and its tax structure, as well as in the measures described as 'positive action', has gender biases that perpetuate the role of women in the field of care, entailing opportunity costs in the development of their professional and personal life. The analysis of some of the most paradigmatic examples and the proposal of various solutions based on the feminist economy and gender taxation are the subject matter of this paper.
\end{abstract}

Keywords: Financial System - Budget - Tributes - Gender - Gender Biases.

(*) Nota del Editor: este artículo fue recibido el 13 de octubre de 2019 y su publicación aprobada el 4 de noviembre de 2019.

${ }^{* *}$ Doctora por la Universidad de Extremadura, España. Profesora Sustituta de Derecho Financiero y Tributario en la Universidad de Extremadura. Docente en la Facultad de Derecho y Facultad de Empresa, Finanzas y Turismo. Correo electrónico: jdcalvarro@ unex.es 


\section{El contexto social y la igualdad de género}

Este artículo analiza algunos de los sesgos de género que presenta el sistema financiero y tributario español, y las graves consecuencias que presumiblemente se derivan de ellos y que se pueden resumir en: primero, la perpetuación de determinados roles de género mujer reproductora, hombre productor y; segundo, una realidad social que supera al derecho y, en este caso, al derecho financiero y tributario. Las propuestas de solución ante estos desajustes serán las conclusiones del artículo desde la perspectiva de la economía feminista y la fiscalidad de género.

El contexto social ha sufrido multitud de cambios en el siglo XXI, sobre todo para las mujeres que han pasado de ocuparse exclusivamente del ámbito doméstico y de cuidados a introducirse con mucha dificultad y de forma aún desigual en el mercado laboral, sin que exista una corresponsabilidad de los varones hacia las labores de cuidado(1). A esto se añade que el empleo femenino presenta características propias: (i) un alto grado de vulnerabilidad a las situaciones de desempleo (Ruiz, 2013, pág. 11), (ii) una tasa de paro superior a la masculina; (iii) la mayoría del empleo a tiempo parcial femenino, porque no lo encuentran a tiempo completo o porque lo eligen para poder asumir el cuidado de hijos y dependientes; y (iv) la crianza de los hijos penaliza a las mujeres en el ámbito laboral. Todas estas circunstancias hacen que las mujeres dispongan de menores niveles de renta que los hombres, tengan altos índices de dependencia económica y sean más proclives a la pobreza.

La mujer del siglo XXI padece el síndrome de superwoman, porque es como una malabarista de circo que se encarga de su hogar, de los hijos y dependientes y, además, si puede, trabaja fuera del ámbito doméstico en empleos que, en algunos casos, son precarios o a tiempo parcial. Con un poco de suerte, recibirá la "ayuda" de su cónyuge, y se denomina ayuda, porque el entorno del hogar no es responsabilidad del varón y su participación se entiende como un regalo y no como una obligación compartida. Aunque la sociedad va cambiando, existen aspectos que lo hacen muy lentamente y la consecuencia es que se desaprovecha el cincuenta por ciento del capital humano en un ejercicio de ceguera social que se mantiene desde hace años.

El ordenamiento jurídico financiero es reflejo de la situación de partida, pero no asume todos los cambios que se están produciendo socialmente, lo que implica un tratamiento fiscal desigual o que al menos no coadyuva a la integración de las mujeres en el mercado productivo. Esto es lo que algunas autoras como García Calvente y Ruiz Garijo (2010) llaman androcentrismo fiscal.

La desigualdad derivada del modelo androcéntrico implica la división de hombres y mujeres en los ámbitos productivos y reproductivos respectivamente, perpetrándose de facto la exclusión de las mujeres del ámbito productivo (las tasas de paro femenino hablan por sí solas). Esta realidad les hace estar más expuestas a la situación de pobreza (García, 2012, pág. 88) y a la exclusión social, como ya se ha mencionado.

La Unión Europea, de la que España es Estado miembro, proclama la igualdad entre hombres y mujeres como un principio fundamental(2) y, a nivel constitucional, el artículo 14 proclama la igualdad como principio y derecho fundamental que, en relación con el artículo 9.2, establece una obligación para los poderes públicos de garantizar su ejercicio pleno y sin obstáculos. De esta manera, la igualdad material comporta una postura activa por parte de los poderes públicos ${ }^{(3)} y$, en este caso concreto, al poder financiero (Fernández \& Sánchez, 2010, pág. 78), que lo asume a través del establecimiento de determinados beneficios fiscales. El poder tributario puede ser impulsor de políticas públicas de género en tanto los sistemas fiscales son reflejo de los aspectos económicos, políticos y sociales de un determinado momento y de un determinado lugar.

A pesar de estas previsiones, es necesario analizar dichas políticas porque en muchos casos no son neutrales, sino que conllevan un cierto sesgo de género, manteniendo una situación injusta en las relaciones entre hombres y mujeres (Lucas, 2018, pág. 177).

(1) "La incorporación al modelo de participación dual no ha ido acompañado de una corresponsabilidad en las labores del hogar. Esta asimetría entre el ámbito laboral y familiar, ha llevado a una errónea catalogación de "la conciliación" (en realidad, el objetivo) como un problema de mujeres, desviando la atención sobre la desafección de los hombres por la esfera doméstica, origen de buena parte de las desigualdades y discriminaciones en el ámbito laboral y de la acumulación de responsabilidades que recaen sobre las mujeres, deteriorando su calidad de vida". Consejo Económico y Social (2011). Tercer Informe sobre la situación de las mujeres en la realidad sociolaboral española. Madrid: Consejo Económico y Social.

(2) Artículo 21 y 23 de la Carta de los Derechos Fundamentales de la Unión Europea.

(3) Artículo 9.2 Constitución Española. 
En este aspecto, hay que discernir si estas políticas en pro de la igualdad material realmente son eficaces en orden al objetivo que persiguen y; por otro lado, si el sistema financiero español es desigual desde el punto de vista del género.

$Y$ no es este un tema baladí, porque, si como afirman investigadoras de prestigio como Pazos Morán (2011), la igualdad es un presupuesto indispensable para una economía productiva y un desarrollo sostenible, y la desigualdad es el principal lastre de nuestra economía, no se entiende que no se tenga en consideración a la hora de adoptar políticas públicas, entre las que se encuentran las fiscales y presupuestarias, lo que subraya la necesidad de un sistema neutro y eficaz con respecto al género o que, al menos, elimine sus sesgos de género.

\section{Análisis de los sesgos de género en el sistema financiero y tributario}

El poder financiero como instrumento de políticas públicas, además de su finalidad prioritaria como generador de ingresos y gastos públicos, será objeto de este epígrafe. Posteriormente, se realizará el análisis de los sesgos de género más llamativos del sistema financiero, tanto desde la vertiente de los ingresos como desde la vertiente de los gastos, así como el posicionamiento de la economía feminista y la fiscalidad de género.

La primera cuestión que corresponde dilucidar, antes del desarrollo de los puntos anteriormente mencionados, es qué son los sesgos de género. Para Stotsky (2005) se debe diferenciar entre los sesgos de géneros explícitos e implícitos (pág. 1). Los primeros son diferencias existentes entre las normas jurídicas en función del género, mientras que los implícitos son las diferencias en la forma en que el sistema fiscal afecta al bienestar de hombres y mujeres. La segunda cuestión responde a cómo es la estructura del sistema financiero para, posteriormente, centrar el análisis en los sesgos de género que presenta, tanto implícitos como explícitos.

\subsection{El sistema financiero y tributario español como generador de políticas públicas en favor de la igualdad de género}

Para entender el marco jurídico de referencia, deviene necesario un breve estudio del sistema financiero y tributario español. La doctrina define el objeto del derecho financiero como el análisis de una determinada actividad de los entes públicos que se circunscribe a la obtención de ingresos y la distribución y control de gastos de los recursos monetarios (Calvo, 2009, pág. 47); es decir, se detraen recursos de los ciudadanos en función de su capacidad económica para atender a las necesidades de la población, conforme a los principios de equidad y eficiencia. Por el lado de los ingresos, adquiere una especial importancia el sistema tributario que define qué hechos imponibles son susceptibles de gravamen y quienes están obligados a satisfacerlo. Por la vertiente de los gastos, el principal instrumento es el presupuesto, entendido como la planificación de la actividad financiera general de un determinado ente público en un concreto periodo de tiempo (Merino, 2012, pág. 30).

El ordenamiento tributario atribuye un conjunto de potestades a determinadas instituciones públicas y a entes públicos territoriales, cuya concreción y complejidad depende de la organización política territorial del Estado y es en este aspecto donde está la mayor complejidad del caso español, porque es un Estado descentralizado con tres niveles tributarios conformados por el Estado, las Comunidades Autónomas y los Entes Locales que no tienen la misma definición ni el mismo contenido, aunque comparten fuentes, normas comunes y establecen relaciones entre ellos. Sin olvidar la integración de España en la Unión Europea que define la existencia de otro poder tributario más.

El esqueleto o la estructura del sistema financiero y tributario español viene recogido constitucionalmente en los artículos 133 y 134. La potestad originaria para establecer los tributos corresponde exclusivamente al Estado mediante ley. Las Comunidades Autónomas y las Corporaciones Locales podrán establecer y exigir tributos de acuerdo con la Constitución y las leyes.

El sistema tributario estatal es el más importante, porque el Estado, titular del poder legislativo y ejecutivo central en los países descentralizados, es el último responsable de la financiación pública (Calvo, 2015, pág. 397). Por tanto, los tributos que lo forman son los más significativos por su aplicación en todo el país, su incidencia en la economía y la política social, así como su relevancia recaudatoria (Calvo \& Calvo, 2019, pág. 441). Entre ellos están el Impuesto sobre la Renta de las Personas Físicas, el Impuesto sobre la Renta de los no residentes, el Impuesto sobre el Patrimonio, el Impuesto sobre el Valor Añadido y los Impuestos Especiales.

En el nivel autonómico, hay que tener presente que la Constitución determina la potestad de establecer sus propios tributos, limitado a hechos imponibles no gravados 
por el Estado ni por la Administración Local. Su fundamento se encuentra en el artículo 2 de la Constitución española que garantiza el derecho a la autonomía de las nacionalidades y regiones que la integran y la solidaridad entre todos ellas, mientras que el artículo 156 del texto constitucional las dota de autonomía financiera, lo cual se encuentra desarrollado normativamente en los artículos 6 y 9 de la Ley Orgánica 8/1980, de 22 de septiembre, de Financiación de las Comunidades Autónomas. Además, reciben la cesión de recaudación y de competencias normativas por parte del Estado. En resumen, las Comunidades Autónomas se financian fundamentalmente por la cesión de parte de la recaudación de los impuestos estatales, por los tributos cedidos por parte del Estado y los tributos propios ${ }^{(4)}$.

El artículo 140 de la Constitución española garantiza la autonomía de los municipios, incluyendo la atribución implícita de poder tributario. Esto permite a los municipios generar sus propios recursos dinerarios y la financiación de sus servicios, pero los Entes Locales no tienen potestad legislativa, por lo que la regulación legal es estatal, dejando a la decisión municipal la entrada en vigor de los llamados impuestos potestativos y la determinación de los elementos cuantitativos de los impuestos tanto potestativos como obligatorios. Los tributos propios de las Haciendas Locales son su principal elemento de financiación.

La regulación del presupuesto u ordenación jurídica de los gastos públicos debe cumplir varios principios entre los que destaca el principio que realiza una asignación equitativa de los recursos públicos, cuya programación y ejecución responderán a los criterios de eficiencia y economía de los que se infiere una racionalización del empleo de los gastos públicos. Esto debe tener en consideración todas las necesidades del país, debe ser equilibrado y con el menor coste para la obtención de determinados objetivos. El principio de gasto equitativo tiene una clara proyección en el género cuando se relaciona con la idea de la determinación de un gasto que posibilite la realización de una igualdad real y efectiva. Al igual que el Estado aprueba anualmente su programa de ingresos y gastos, lo ejecuta y se ejerce el oportuno control sobre el mismo, también los entes territoriales, Comunidades Autónomas y Entes Locales, realizan lo propio.

La versión que se ha dado hasta ahora del sistema fiscal es el de una estructura cuyo fin es el recaudatorio, es decir, genera ingresos con los que sostiene los gastos públicos. Sin embargo, como se ha señalado, puede ser un catalizador de políticas públicas con vocación social, porque se admite que a través del poder tributario se busque fines extrafiscales orientados a objetivos sociales y a la integración de colectivos en riesgo de exclusión, a través de la propia estructura impositiva o la introducción de las llamadas medidas de acción positiva que se establecen temporalmente para suprimir o corregir desigualdades y que tienen un importante peso específico en el análisis de la fiscalidad desde una perspectiva de género. Por tanto, puede ser una actividad instrumental para financiar políticas que persigan determinados objetivos y puede, por sí mismo, perseguir determinados fines que la sociedad demanda entre los que se encuentran el ejercicio efectivo del principio de igualdad. En la última reforma del Impuesto sobre la Renta de la Persona Física, en su exposición de motivos, se hacía expresa referencia a la igualdad de género y la protección de la familia, pero esta vinculación entre el ámbito fiscal y la igualdad de género no es nueva y ya fue señalada por Olympe De Gouges en el siglo XVIII(5), derivándose de la misma el refuerzo o la mitigación de las desigualdades de género y las relaciones de género asimétricas.

Las medidas de acción positiva implican un trato diferenciado que para sus detractores supone un quiebre del principio de capacidad económica, pero el Tribunal Constitucional considera admisible el establecimiento de tributos que, respetando o flexibilizando el principio de capacidad económica (García, 2012, pág. 88), "respondan principalmente a criterios económicos o sociales orientados al cumplimiento de fines o a la satisfacción de intereses públicos que la Constitución preconiza o garantiza" (Sentencia Tribunal Constitucional 37/1987), y tienen una pervivencia temporal en cuanto "solo se justifica en la realidad de las circunstancias sociales del momento en que se adopta, de manera que su misma eficacia habrá de redundar en la progresiva desaparición del fundamento constitucional del que ahora disfruta. Se trata, en definitiva, de una medida solo constitucionalmente aceptable en tanto que coyuntural, en cuanto responde a la apreciación de una situación determinada".

De la doctrina del Alto Tribunal se infiere que las medidas de acción positiva para ser

(4) Artículos 156 y 157 Constitución Española.

(5) "Para el mantenimiento de la fuerza pública y para los gastos de administración, las contribuciones de la mujer y el hombre son las mismas"; De Gouges, O. (1791). Declaración de los Derechos de la Mujer y de la Ciudadana. 
constitucionalmente admisibles deben ser: (i) proporcionales, (ii) idóneas para los fines pretendidos, y (iii) necesarias, porque no hay otro modo de conseguir el fin. La conclusión es que el principio de igualdad significa que "todos los contribuyentes han de ser tratados no de manera uniforme, sino de acuerdo con sus posibilidades, las cuales vienen dadas por su capacidad económica. Así pues, los iguales han de ser tratados de forma igual y los desiguales de forma desigual” (Fernández, 2010, pág. 28).

Existe una íntima relación entre la exclusión social por razón de género y el principio de igualdad, por lo que está más que justificado la utilización del sistema tributario y el diseño de medidas de acción positiva para evitar la desigualdad de género. Lo que se cuestiona es si el sistema financiero y las medidas de acción positiva incluidas en él son eficaces en orden a los objetivos que persiguen, y para ello se debe analizar cómo afecta a la igualdad entre hombres y mujeres (García, 2012, pág. 92). Es decir, como se comprobará en las siguientes páginas, medidas que apriorísticamente benefician a las mujeres pueden ser en el fondo perpetradoras de una situación en la que estas son reducidas al ámbito de los cuidados, que, como afirma Lucas Duran (2018), "deben merecer un reproche desde la perspectiva de la igualdad de género” (pág. 178).

En palabras de Fernández Amor \& Sánchez Huete (2010), lo que se pretende revisar es "la capacidad del Derecho Financiero para establecer medidas equitativas en materia de género; bien desde la perspectiva del ingreso, a través de la extrafiscalidad del tributo; bien desde la perspectiva del gasto público, a través de la potencialidad exegética del principio de equidad interpretado en clave de género" (pág. 78).

Sin embargo, más allá del ámbito financiero y tributario, es interesante el punto de vista de la economía feminista que postula la eliminación de la división sexual del trabajo. El objetivo que se pretende es que las personas sean a la vez cuidadoras y sustentadoras, y la corresponsabilidad en las medidas de conciliación de la vida laboral y familiar. Jurídicamente implica deconstruir todas aquellas normas que tienen en su centro la división sexual de tareas o la división en esferas masculinas o femeninas según su área de actuación.

\subsection{Los sesgos de género en el sistema financiero y tributario. Algunas consideraciones generales}

El análisis que someramente se va a desarrollar en este apartado es complicado, porque así se puede calificar la distinción entre políticas verdaderamente neutrales que coadyuvan a la igualdad entre sexos y aquellas que tienen "apariencia de neutralidad" (Pazos, 2008), ya que, si se profundiza en determinados aspectos, medidas así etiquetadas, no lo son, ahondando en el mantenimiento de las desigualdades y los estereotipos de género. Por otra parte, perviven en algunas figuras impositivas disposiciones que reproducen roles de género o no están ajustados a la realidad social actual, sin olvidar algunos aspectos presupuestarios interesantes en relación a la perspectiva de género. Para aportar mayor claridad a la exposición, se va a distinguir entre la vertiente impositiva y la vertiente presupuestaria.

\subsubsection{Los sesgos de género en el sistema impositivo}

El estudio se centrará en el sistema tributario estatal, en las principales figuras impositivas. Principalmente se hará hincapié en aquellas que, en palabras de Ruiz Garijo (2013), "en lugar de ser una forma de luchar contra las discriminaciones de género, las retroalimentan" (pág. 17).

El Impuesto sobre la Renta de las Personas Físicas es un impuesto directo que grava la obtención de rentas por las personas físicas, atendiendo a circunstancias familiares y personales. Se considera la columna vertebral del sistema fiscal español y es un tributo paradigmático para el estudio de los sesgos de género, no solo desde el punto de vista de la estructura del impuesto, sino por el establecimiento de beneficios con fines extrafiscales o como reflejo de medidas de acción positiva.

El aspecto más controvertido desde el punto de vista del género es la tributación conjunta. Aunque la norma establece la tributación individual( ${ }^{(6)}$, existe la posibilidad de que las personas integradas en la unidad familiar tributen de forma conjunta. Cuando se habla de unidad familiar, se hace referencia a la que establece la ley que regula el impuesto, la cual excluye esta posibilidad a las parejas de hecho o a las familias monoparentales, y descarta de facto a las familias no convencionales o tradicionales, lo cual es una regla no escrita del sistema tributario español y, en especial, de este impuesto. Una vez más se observa la falta de sintonía entre la fiscalidad y la sociedad.

Durante un periodo de tiempo fue un régimen obligatorio, pero se consideró inconstitucional porque discrimina a los casados frente a los solteros ${ }^{(7)}$, penalizando a

(6) Artículo 11 Ley 35/2006, de 28 de noviembre, del Impuesto sobre la Renta de las Personas Físicas.

(7) Sentencia Tribunal Constitucional 45/1989. 
las parejas en la que ambos miembros trabajan, porque tienen más renta conjunta; por estas razones se estableció a partir de 1989 su optatividad ${ }^{(8)}$.

La tributación conjunta implica la suma de las rentas de ambos cónyuges en caso de que los dos las perciban y la posibilidad de beneficiarse de una deducción en la cuota de 3 400 euros atendiendo a la norma en vigor. La suma de las rentas supone gravarlas a un tipo marginal superior, por lo que afecta al segundo perceptor de renta que ve cómo se grava el primer euro de su salario al tipo marginal de su cónyuge; sin embargo, si opta por la tributación individual, renuncia a la reducción de 3400 euros (Cubero et al., 2009). La consecuencia más negativa es que la mujer decida no acceder al mercado laboral o abandonarlo ante un incremento del gravamen que difícilmente compensa la pérdida del trabajo doméstico. Se habla de la afectación de esta medida a la mujer, porque suelen ser el segundo perceptor de renta, por lo que el sesgo de género es evidente.

Es desolador mantener una medida, aunque sea opcional, cuyo fundamento, de otros tiempos, es "la existencia o bien de una persona del sexo femenino que no trabaja y no aporta, en consecuencia, rentas monetarias a la 'unidad familiar' o si dispone de rentas, éstas son esporádicas y marginales respecto del mayor contribuyente en esa 'unidad familiar': el padre de familia" (Carbajo, 2009). Es reprochable la perpetuación de esta medida, a pesar de las modificaciones legales, cuando desde distintos organismos públicos ${ }^{(9)}$ se recomienda la tributación individual como elemento indispensable para conseguir la igualdad de trato, siendo reconocido por distintos países de nuestro entorno que han eliminado la tributación conjunta de sus impuestos sobre la renta.

Por otra parte, la tributación separada de los cónyuges o tributación individual tiene un efecto positivo sobre el cónyuge que percibe menos rentas, porque aumenta su poder de negociación en los hogares. Asimismo, sería interesante la valoración económica del trabajo no remunerado para no subrayar la dependencia frente al cónyuge más productivo, tal y como propugna la economía feminista. Sin embargo, la integración del trabajo doméstico y de cuidados en los modelos o en los procesos económicos tiene un alto grado de dificultad, debido, entre otros aspectos, a la falta de voluntad, falta de cuantificación y la falta de valoración (Carrasco, 2011, pág. 216) que, en ningún caso, implica su estimación en clave femenina. Himmelweit (2002) propone considerar el trabajo doméstico como rendimiento en especie dentro del Impuesto sobre la Renta, aunque el principal problema, una vez más, es el método de valoración.

La deducción por maternidad del artículo 81 Ley 35/2006, de 28 de noviembre, del Impuesto sobre la Renta de las
Personas Físicas, es una medida de acción positiva en favor de las mujeres madres de hijos menores de tres años que realicen una actividad por cuenta propia o ajena. La deducción se aplica en la cuota diferencial e implica una disminución en la misma de 1 200 euros o un ingreso mensual de 100 euros. Aunque apriorísticamente su finalidad es el fomento de la natalidad y la compensación de los gastos derivados de la maternidad, presenta varios aspectos negativos. En primer lugar, su no extensión a los padres, por lo que de facto relaciona cuidado de hijos y mujer; segundo, si pretende la incorporación de la mujer al mercado de trabajo, debería extenderse a las mujeres con hijos mayores de tres años, cuyos gastos pueden ser incluso superiores; tercero, la cantidad no incentiva la incorporación de la mujer al mercado de trabajo y; cuarto, excluye al colectivo más vulnerable: las mujeres madres que no trabajan por cuenta propia o ajena, porque, o bien no han accedido al mercado de trabajo o bien se dedican al trabajo doméstico que no es valorado a efectos tributarios. Por tanto, se deben incluir otras medidas 0 , al menos, modificar las existentes para evitar los sesgos de género. En este sentido, se propone una prestación por cuidados de hijos (Pazos, 2006, pág. 30) sin incidir en el género del progenitor.

El análisis es parecido en el caso de la deducción por circunstancias familiares regulado en el artículo 81 de la Ley 35/2006, de 28 de noviembre, del Impuesto sobre la Renta de las Personas Físicas. Aunque en este caso no se hace mención del género del beneficiado por esta medida, sí se refiere a un ámbito, el de los cuidados, el cual se encuentra muy feminizado, por lo que la mayoría de estas deducciones tienen nombre de mujer.

Ambas medidas, para sus detractores, implican una suerte de subvención cuyo objeto es el mantenimiento de la mujer en el ámbito doméstico o, en el mejor de los casos, su no abandono, aunque trabaje en el ámbito productivo; por tanto, perpetúan ciertos roles de género.

(8) A partir de Ley $20 / 1989$, de 28 de julio.

(9) Comisión Europea; Nuevo Programa de Acción Comunitaria 1982-1985; COM (81)758 final. 
Como se explicó en su momento, existen impuestos estatales que son cedidos a las Comunidades Autónomas, tanto en su recaudación como en la regulación de algunos aspectos normativos. En el caso del Impuesto sobre la Renta de las Personas Físicas, las Comunidades Autónomas pueden establecer deducciones en la cuota del impuesto. La Comunidad Autónoma de Extremadura ha establecido una serie de deducciones que apoyan a la familia y a determinados colectivos: (i) deducción por cuidado de familiares con discapacidad, (ii) por gastos de guardería para hijos menores de cuatro años y (iii) por partos múltiples. A primera vista, son interesantes, porque no discriminan por género, pueden ser beneficiarios hombres y mujeres, indistintamente. Sin embargo, ahondando en la deducción por cuidado de familiares con discapacidad, se observa que uno de sus requisitos es la convivencia, presentando un efecto perverso y trasladando a las familias $y$, fundamentalmente a las mujeres de la familia, el cuidado de las personas con discapacidad, obligación de los poderes públicos a través del establecimiento de servicios públicos suficientes y de calidad.

El establecimiento de deducciones o beneficios fiscales debe ser restringido, no deben incidir en los roles prefijados hombre productor - mujer reproductora, ni en las relaciones, excepto, de forma acotada, las que afectan a menores y dependientes. Pero pueden ser interesante en orden a la igualdad de géneros, siempre y cuando se plantee bajo determinadas premisas: primero, aplicable a hombres y mujeres; segundo, respetando el principio de capacidad económica y; tercero, la modulación de la deducción en función de determinadas circunstancias. Fernández Amor (2010) pone el acento en la equiparación de colectivos en lo laboral o de corresponsabilidad en el cuidado de hijos (pág. 35).

El impuesto sobre el valor añadido, paradigma del impuesto indirecto, no tiene en cuenta las circunstancias personales. Es un impuesto sobre el consumo que posee una gran capacidad recaudatoria. Sin embargo, cabe la posibilidad de introducir un sesgo de género en productos que, exclusivamente o de forma mayoritaria, compren mujeres $u$ hombres. El caso más paradigmático son los tampones o productos de higiene femenina que tributaban al $10 \%$, considerándose que, al ser un bien de primera necesidad para las mujeres que veían aumentar su cesta de la compra por esta diferencia porcentual, debían tributar al $4 \%$, como posteriormente sucedió. Se considera un sesgo de género, porque: primero, las mujeres tienen una posición económica de desventaja, por lo que el impuesto sobre el valor añadido provoca una mayor incidencia en ellas; segundo, las normas sociales y el rol de cuidados de las mujeres producen distintos patrones de consumo en función del sexo. Por tanto, gravar un producto de consumo exclusivamente femenino a un tipo general tiene dos implicaciones; en primer lugar, las mujeres afrontan un gasto superior por un producto básico que deben consumir independientemente del nivel de renta, por lo que se debe evitar la falta de acceso a estos productos por la situación financiera y; en segundo lugar, el hecho de no considerarlos productos básicos indica el no reconocimiento a las mujeres y a sus necesidades (Institut per a léstudi i la transformación de la vida quotidiano, 2016, pág. 37-39).

Sin embargo, algunos autores (Stotsky, 2005, pág. 15), aunque admiten la existencia de un sesgo implícito, consideran que es muy difícil de determinarlo porque esos bienes, habitualmente, se adquieren en el contexto del hogar y su repercusión depende del proceso de toma de decisiones de cada hogar.

Este mismo argumento se traslada a los Impuestos Especiales. Se considera que el alcohol y el tabaco son consumidos de forma mayoritaria por los hombres, por lo que habría un sesgo de género que afecta negativamente al contribuyente varón, pero depende del proceso de toma de decisiones de cada hogar. Asimismo, hay que matizar que la elevación del tipo impositivo en estas figuras tributarias no tiene nada que ver con el género, sino con el objetivo de disuadir al contribuyente de determinadas conductas que son perjudiciales para su salud y; por tanto, tienen consecuencia sobre el gasto público sanitario.

\subsubsection{Los sesgos de género en la vertiente presupuestaria}

El gasto público también debe abordarse desde una perspectiva de género. Se debe partir del artículo 31 de la Constitución española que en su apartado 2 establece que "el gasto público realizará una asignación equitativa de los recursos públicos y su programación y ejecución responderán a los criterios de eficiencia y economía". Esta referencia a la asignación equitativa del gasto debe atender, según Lucas Duran (2012), primero, a la satisfacción de las necesidades mínimas de la comunidad; segundo, a la ausencia de arbitrariedades y desviaciones de poder y; tercero, debe verificarse el principio de igualdad que implica que se financie de forma desigual situaciones diversas y que requieran distinto trato (pág. 203). Estas situaciones diversas se pueden 
concretar en destinatarios con una riqueza menor o colectivos especialmente desfavorecidos, como pueden ser las mujeres que tienen un mayor riesgo de exclusión social y económica. En consecuencia, "la programación o ejecución de un gasto público que no persiga activamente la igualdad de género no se encuadra dentro de los criterios de justicia previstos por nuestra Constitución” (Lucas, 2012, pág. 207).

En los recortes presupuestarios que se realizaron durante el periodo de crisis económica y que, aún hoy, se siguen manteniendo en muchos ámbitos, se observó su mayor incidencia en las mujeres por varias razones: primero, presenta una oferta laboral más restringida; segundo, en algunos casos, la mujer con cargas familiares consideran que le compensa más retornar al hogar y a los cuidados que desempeñar empleos feminizados, peor remunerados, a tiempo parcial y, en muchos casos, en situación de precariedad y; tercero, en caso de desempleo o paro, acceden menos al subsidio por las razones ya mencionadas. La consecuencia es la feminización de la pobreza (Ruiz, 2013, pág. 3).

Se aboga, por tanto, por una evaluación y elaboración de los presupuestos con perspectiva de género, tal y como establece la Ley Orgánica 3/2007, de 22 de marzo, para la igualdad efectiva de mujeres y hombres, bajo la premisa de que el impacto de las medidas presupuestarias es distinto en hombres y mujeres, probablemente por su distinta posición social y económica (Ruiz, 2013, pág. 24). Los recortes realizados por los gobiernos en los años de crisis económica en áreas como la salud, la educación, la infraestructura y los servicios básicos suponen una transferencia de la carga de los cuidados a las familias donde, dada la división sexual del trabajo, implica una imposición adicional sobre las mujeres, tradicionalmente las que se encargan de ese ámbito (Rodríguez \& Elson, 2012).

Desde la vertiente del gasto, entendida ésta en sentido amplio, se pueden establecer algunas propuestas (Lucas, 2018, pág. 193): (i) bonificaciones en las cotizaciones de la Seguridad Social para las empresas que contraten mujeres o para ellas si deciden emprender y (ii) medidas específicas que reconozcan los años dedicados al cuidado de familiares como años cotizados, y que se reconozca y habilite su formación.

Como resumen de los diferentes apartados de este epígrafe, las medidas analizadas para sus partidarios son escasas, pero para sus detractores no fomentan políticas de igualdad, sino que suelen promocionar políticas de familia que relegan a la mujer al tradicional papel de cuidadora (Fernández, 2010, pág. 32). En palabras de Pazos Morán (2016), son incentivos con un importe miserable, no generan prestaciones por desempleo y no fomentan que las mujeres consigan un empleo de calidad.

Por tanto, vistas las posturas contrapuestas, una de las cuestiones a plantear es si se debe reivindicar un tratamiento singularizado para las mujeres o se debe trabajar por un sistema financiero neutro; en palabras de Pazos Morán (2016), "con la neutralidad basta", porque no es necesario establecer medidas para mujeres, sino eliminar las practicas viciadas que suponen una desigualdad explícita o implícita para la mujer.

En este sentido, es muy interesante uno de los aspectos que preconiza la economía feminista y resaltado por la Unión Europea, véase su "Libro Blanco sobre Crecimiento, Competitividad y Empleo: la individualización de los derechos sociales y fiscales", acentuando la necesidad de "garantía de que los sistemas de seguridad social y de impuestos reflejen el hecho de que los hombres y las mujeres puedan actuar como individuos a la hora de buscar empleo y compaginar la vida laboral y familiar" (Comisión de las Comunidades Europeas, 1993, pág. 146), mediante la eliminación de cualquier política fiscal y de protección social "potencialmente discriminatoria que pueda impedir la participación equitativa de la mujer" (De Villota \& Ferrari, 2001).

La individualización de los derechos fiscales implica considerar a la persona como autónoma, desvinculada de sus lazos familiares $\mathrm{o}$, al menos, de forma restringida, y se interpreta como "el derecho a la neutralidad fiscal y a disfrutar de idénticas deducciones y desgravaciones independientemente del sexo y del estado civil y del contribuyente" (De Villota \& Ferrari, 2001), y entendiendo el ámbito de cuidados dentro de los límites de la actuación del sector público o, en su defecto, de la corresponsabilidad. Sin embargo, en el sistema fiscal y presupuestario se toma a la familia como elemento configurador, y no cualquier familia, sino la tradicional formada por sustentador principal y esposa dependiente (Pazos, 2006, pág. 30).

A corto y medio plazo, el mantenimiento del actual sistema fiscal no es óbice para que no se mejore a través de determinadas acciones y políticas presididas por la transversalidad, principalmente en dos ámbitos: la corresponsabilidad y una mayor oferta de servicios públicos asistenciales $y$, en el plano más estrictamente fiscal, la eliminación de aquellas medidas fiscales que supongan un gravamen o, al menos, una reducción de incentivos para el trabajo 
del miembro de la pareja, cuya remuneración sea menor, que normalmente es mujer. El ejemplo más claro, tal y como se ha puesto de manifiesto en estas páginas, es la tributación conjunta del Impuesto sobre la Renta de las Personas Físicas.

\section{Posibles soluciones desde la fiscalidad de género y la economía feminista}

Las soluciones que se van a desgranar han de ser complementarias a distintas acciones en otras áreas de actuación, porque la transversalidad es el concepto clave e implica que las "políticas públicas tengan en cuenta el género, favorezcan la igualdad y reconozcan las diferentes necesidades de las mujeres y de los hombres en la misma medida" (Pazos, 2006, pág. 5), lo que conlleva un proceso de adaptación y de evaluación de las políticas a los fines de la igualdad.

Una transversalidad que implica el desarrollo de servicios públicos suficientes para que las familias y más concretamente las mujeres de la familia no suplan al Estado en las necesidades de cuidado. Una transversalidad que pone el acento en cambios de conducta para transformar las desigualdades de género existentes. Se habla de desaprender lo que significa ser hombre o mujer, se habla del género como arquetipos construidos socialmente. En cualquier caso, si lo que se pretende es una sociedad más igualitaria y sostenible, es necesario e imprescindible transcender el género. En este sentido la corresponsabilidad de hombres y mujeres en los ámbitos productivos y reproductivos es la clave.

En el plano más estrictamente financiero y tributario, en conexión con lo que se acaba de plantear, se pueden trazar una serie de medidas que, en algunos casos, pueden desarrollarse paralelamente en el tiempo y que implican una adecuación del actual sistema financiero y tributario a la perspectiva de género, distinguiendo entre la vertiente impositiva y presupuestaria.

Es indispensable que el sistema tributario español y su ordenamiento se ajusten a la nueva realidad social, a los nuevos modelos de familia y a los cambios producidos por la incorporación normalizada de la mujer al mercado de trabajo. Esto implica dos acciones fundamentales: en primer lugar, la eliminación de aquellas medidas que, como la tributación conjunta, tuvieron su justificación en un momento social anterior, pero que ahora carecen de cualquier fundamento social, jurídico o incluso recaudatorio y; en segundo lugar, el análisis de las medidas de acción positiva, deducciones y demás beneficios fiscales desde la perspectiva de género para evitar efectos perversos, porque no todo lo que lleva la etiqueta de género coadyuva a la igualdad entre hombres y mujeres.

La anterior afirmación no implica que no se utilicen las medidas de acción positiva, sino que es necesario, y no hay otra forma de conseguir los objetivos propuestos, que su diseño tenga en cuenta las siguientes premisas: (i) que beneficie al colectivo al que se dirige; (ii) no perpetúe determinados roles y (iii) establezca la igualdad de oportunidades entre hombres y mujeres, o no tenga en cuenta el género a la hora de su definición.

Las propuestas anteriores deben convivir con el establecimiento de otras medidas que, más a largo plazo, y de una forma progresiva, tengan como objetivo el diseño de un sistema tributario neutro. Para ello, es indispensable la individualización de los derechos y obligaciones, evitando, en lo posible, las referencias al género, y considerando las medidas de acción positiva de temporalidad finita en tanto el sistema tributario vire hacia la neutralidad, hacia la individualización de derechos y obligaciones y se fundamente en la capacidad económica y no en el género a la hora del diseño de sus beneficios fiscales.

En la vertiente del gasto o presupuestaria, en cambio, frente a la neutralidad del sistema impositivo, es fundamental el análisis de los presupuestos y de la distribución del gasto público desde la perspectiva de género, generalizando que su elaboración tenga en cuenta este criterio como principio, mientras no exista una permeabilidad entre los ámbitos doméstico y productivo.

La tarea es ardua y apenas se han dado los primeros y no siempre acertados pasos, pero existen determinados cambios sociales que no se pueden parar, e influyen proactivamente en los cambios jurídicos, generando retos para el derecho y la actuación de los poderes públicos.

\section{Referencias bibliográficas}

Calvo Ortega, Rafael (2009). Curso de derecho financiero y tributario. Madrid: Thomson Reuters.

Madrid: Civitas.

(2015). Curso de Derecho Financiero.

Calvo Ortega, Rafael \& Calvo Vérgez, Juan (2019). Curso de Derecho Financiero (23ra ed.). Madrid: Thomson Reuters.

Carbajo Vasco, Domingo (2009). Impuestos y género. Algunas reflexiones. Crónica Tributaria, 132, pág. 83-92.

Carrasco, C.; "La economía del cuidado: planteamiento actual y desafíos pendientes"; Revista de Economía Crítica n¹1; Barcelona; 2011. 
Comisión de las Comunidades Europeas (1993). Crecimiento, Competitividad y Empleo. Retos y pistas para entrar en el siglo XXI. Libro Blanco (Suplemento 6/93). Bruselas: Oficina de Publicaciones Oficiales de las Comunidades Europeas.

Consejo Económico y Social (2011). Tercer Informe sobre la situación de las mujeres en la realidad sociolaboral española. Madrid: Consejo Económico y Social.

Cubero Truyo, Antonio, Jiménez Navas, María \& Sanz Gómez, Rafael (2009). ¿Perspectiva de género en los impuestos? La discriminación positiva en el IRPF. En I. Vásquez, C. Flecha, A. Guil \& M. Cala (coord.), Investigación y género, avance en las distintas áreas de conocimiento: I Congreso Universitario Andaluz Investigación y Género. Sevilla: Universidad de Sevilla. Recuperado el 10 de septiembre de 2019, de http://hdl.handle. net/11441/40284

De Gouges, Olimpia (1791). Declaración de los Derechos de la Mujer y de la Ciudadana. Recuperado el 10 de septiembre de 2019, de http:// clio.rediris.es/n31/derechosmujer.pdf

Institut per a léstudi i la transformación de la vida quotidiano (2016). La fiscalidad en España desde una perspectiva de género. De la Fuente, María (direc.). Barcelona: Institut per a léstudi i la transformación de la vida quotidiano.

De Villota, Paloma \& Ferrari, Ignacio (2001). Análisis de la política fiscal desde la perspectiva de género. En VIII Encuentro de Economía Pública. Cáceres: s.n. Recuperado el 26 de agosto de 2019, de https://dialnet.unirioja.es/servlet/ articulo?codigo $=3141097$

Fernández Amor, José (2010). El poder tributario como instrumento para la igualdad: la extrafiscalidad y la perspectiva de género. En D. Heim \& E. Boledón (coord.), Derecho, Género e Igualdad. Cambios en las estructuras jurídicas androcéntricas (Vol. I). Barcelona: Grupo Antígona UAB.

Fernández Amor, José \& Sánchez Huete, Miguel (2010). La realización del principio de igualdad de género por medio de la extrafiscalidad y el gasto público. En D. Heim \& E. Boledón (coord.), Derecho, Género e Igualdad. Cambios en las estructuras jurídicas androcéntricas (Vol. I). Barcelona: Grupo Antígona UAB.

García Calvente, Yolanda (2012). El Derecho financiero y tributario ante la exclusión social por razón de género. En I. Merino \& E. Manzano, Fiscalidad e igualdad de género. Madrid: Dykinson.
García Calvente, Yolanda \& Ruiz Garijo, Mercedes (2010). Reflexiones acerca de la introducción de la perspectiva de género en el sistema fiscal español: ¿modelo androcéntrico o modelo eficaz para alcanzar la igualdad de género?". En D. Heim \& E. Boledón (coord.), Derecho, Género e Igualdad. Cambios en las estructuras jurídicas androcéntricas (Vol. I). Barcelona: Grupo Antígona UAB.

Himmelweit, Sue (2002). Making Visible the Hidden Economy: The case for gender-impact analysis of economic policy. Feminist Economics 8(1), pág. 49-70.

Lucas Duran, Manuel (2012). La perspectiva de género en la programación del gasto público. En I. Merino \& E. Manzano, Fiscalidad e igualdad de género. Madrid: Dykinson.

(2018). Fiscalidad e igualdad de género. En E. Carmona \& M. Garrido, Diversidad de género e igualdad de derechos. Manual para una asignatura interdisciplinar. Valencia: Tirant lo Blanch.

Merino Jara, Isaac (2012). Derecho financiero y tributario. Parte general. Madrid: Tecnos.

Pazos Morán, María (2006). Impuestos y prestaciones: ¿Qué individualización?. Ponencia a las X Jornadas de Economía Crítica, Barcelona. Recuperado el 4 de septiembre de 2019, de https://xenero. webs.uvigo.es/profesorado/maria_pazos/impuestos.pdf

(2008). Rebaja de impuestos a las mujeres: ¿La acción positiva como arma arrojadiza. Mujeres en red. Recuperado e 4 de septiembre de 2019, de http://www.mujeresenred.net/spip. php?article1375

(2011). Mujer y economía. Ni contigo ni sin ti. Atacc España. Recuperado el 4 de septiembre de 2019, de https://www.attac. es/2011/04/21/mujeres-y-economia-ni-contigo-ni-sin-ti/

(2016). Socorro, a las mujeres nos quieren dar. Blog de María Pazos Morán. Recuperado el 3 de setiembre de 2019, de http:// mariapazos.com/socorro-las-mujeres-nos-quieren-dar/

Rodríguez, Corina \& Elson, Diane (2012). Impuestos para la justicia económica de género. Asociación para los derechos de la Mujer y el Desarrollo. Recuperado el 3 de setiembre de 2019 http://www.forum. awid.org/forum12/es/2012/12/impuestos-para-la-justicia-economicade-genero/

Ruiz Garijo, Mercedes (2013). Políticas fiscales discriminatorias desde una perspectiva de género. Análisis crítico. En A. Gentile (coord.), Actas del IV Congreso Red Española de Política Social (REPS): Las políticas sociales entre crisis y post-crisis. Alcalá de Henares: Universidad de Alcalá de Henares. Recuperado el 2 de setiembre de 2019, de http:// www3.uah.es/congresoreps2013/Paneles/panel3/mercedes.garijo@ urjc.es/TCPonenciaMRG.pdf

Sentencia 37/1987 (Tribunal Constitucional [España], 26 de marzo de 1987).

Stotsky, Janet (2005). Sesgos de género en los sistemas tributarios. En M. Pazos (direc.), Política fiscal y género. Madrid: Instituto de Estudios Fiscales. Recuperado el 2 de septiembre de 2019, de https://www.ief. es/docs/investigacion/genero/FG_Stotsky.pdf 